\title{
Comunicación
}

\section{NIVELES SÉRICOS REFERENCIALES DE BILIRRUBINA, ALT, AST, GGT, PROTEÍNA Y ALBÚMINA EN Aotus nancymae}

\author{
Bruno Ampuero G. ${ }^{1}$ †, Armando Hung Ch. ${ }^{2}$, Olga Li E. ${ }^{3}$ y Hugo Gálvez C. ${ }^{4}$
}

\section{Anstract}

The objective of this work was to establish reference serum values for bilirrubin (total, direct and indirect), alanine amino transferase (ALT), aspartate amino transferase (AST), gamma glutamil transferase (GGT), total protein and albumin in healthy Aotus nancymae primate kept under captivity in the Amazon region of Peru. It was used 30 animals (15 males and 15 females), aged 7 months to 2 years, and raised at the Center of Reproduction and Conservation of Primates, IVITA, San Marcos University, located in Iquitos, Loreto. The animals were trapped with nets, weighed and anesthesyzed for blood collection. Serum values were: Total bilirrubin: $0.76 \pm 0.06 \mathrm{mg} / \mathrm{dl}$; direct bilirrubin: $0.25 \pm 0.03 \mathrm{mg} / \mathrm{dl}$; indirect bilirrubin: $0.52 \pm 0.06 \mathrm{mg} / \mathrm{dl}$; ALT: $30.65+5.5 \mathrm{UI} / \mathrm{L}$; AST: $36.9 \pm 5.69 \mathrm{UI} / \mathrm{L} ; \mathrm{GGT}$ : $23.73 \pm 2.56 \mathrm{UL} / \mathrm{L}$; total protein: $7.53 \pm 0.12 \mathrm{~g} / \mathrm{dl}$; and albumin: $3.83 \pm 0.12 \mathrm{~g} / \mathrm{dl}$. It was concluded that serum values were similar to other results reported in the literature.

Key words: Aotus, owl monkey, bilirrubin, ALT, AST, GGT, total protein, albumin, serum

La necesidad de brindar una mejor calidad de vida al ser humano conlleva a realizar estudios en diferentes áreas, entre las cuales se encuentra el área biomédica donde se emplean especímenes no humanos para ciertas investigaciones, ya que por factores éticos y morales no se pueden realizar directamente en el hombre (Zamecnik, 1975; OPS, 1985).

En base a esto, se buscan especies que permitan hacer estudios comparativos y los primates no humanos constituyen el mejor modelo de experimentación debido a su afinidad con el hombre. Los primates se utilizan para el desarrollo de vacunas, fármacos y el estudio de enfermedades como la hepatitis A, la tuberculosis y el sarampión (Villavicencio $e t$ al., 1986; Whitney, 1990). En Sudamérica, la especie Aotus destaca por su utilidad como modelo experimental para evaluar fármacos en estudios oftalmológicos, de la malaria, de la enfermedad Epstein-Barr, y enfermedades producidas por polyomavirus como el JC y el BK (Baer et al., 1994).

El mono de la especie Aotus habita gran parte de la Amazonía peruana (Aquino y Encarnación, 1986; Soini, 1975), y aunque no sea una especie amenazada ni se encuentre en vías de extinción, existen diversos estudios con respecto al desarrollo y conservación de

\footnotetext{
'Práctica privada

${ }^{2}$ Laboratorio de Patología Clínica, FMV-UNMSM. Dirección actual: Facultad de Veterinaria y Zootecnia, Universidad Peruana Cayetano Heredia.

${ }^{3}$ Laboratorio de Patología Clínica, FMV-UNMSM. E-mail: olga_li2003@hotmail.com

${ }^{4}$ Estación Experimental del Centro de Investigación IVITA-Iquitos, FMV-UNMSM
} 
la misma. Esta especie no sólo contribuye con el ser humano en las investigaciones biomédicas, sino que también constituye un medio de entrada de divisas económicas para el Perú, al igual que desarrollo y trabajo para profesionales y pobladores de la Amazonía.

El objetivo de este estudio fue contribuir al conocimiento de la bioquímica clínica hepática de estos animales, estableciendo parámetros referenciales como los niveles de bilirrubina (total, directa e indirecta), alanino amino transferasa (ALT), aspartato amino transferasa (AST), gamma glutamil transferasa (GGT), proteina y albúmina, que permitirán descartar y reconocer diversos tipos de afecciones que pueden comprometer la función hepática.

El estudio se realizó con animales del Centro de Reproducción y Conservación de Primates (CRCP) del IVITA-UNMSM, localizado en Iquitos, departamento de Loreto. Se emplearon 30 monos Aotus nancymae (15 hembras y 15 machos) nacidos en cautiverio, catalogados como subadultos con edades de 7 meses a 2 años, clínicamente normales. Las hembras no se encontraban en gestación. Los animales estaban alojados en jaulas de $2 \mathrm{~m}^{3}$ ( $2 \times 1 \times 1)$. Se alimentaron con dieta balanceada procesada en el CRCP y presentada en forma de galletas, con insumos a base de harina de soya, harina de trigo, azúcar, aceite, huevos, maní, suplementos vitamínicos, y minerales. El aporte nutricional de la dieta fue de $27.1 \%$ de proteína, $9.8 \%$ de grasa, $3.6 \%$ de fibra cruda, $54.0 \%$ de E.N.N y $5.5 \%$ de cenizas. Además se les proporcionó "maduro" de la región y ocasionalmente naranja. El aprovisionamiento de agua era ad libitum (Galvez-Durand, 2000).

La comprobación del estado de salud de estos animales fue hecha en base a la historia clínica de los animales, la observación del comportamiento (variación de actitudes, etc.), consistencia y color de las heces (presencia de sangre), color de la orina, ausencia o presencia de secreciones nasales, apetito, peso, estado del pelaje, ausencia o presencia de lesiones, traumatismos y presencia de parásitos en general, estado de hidratación de la piel y orificios naturales, y a través de la inspección del alojamiento buscando huellas de sangre (Baer et al.,1994).

Para la toma de las muestras, se inmovilizó a los animales en sus jaulas con una red y se les inyectó clorhidrato de ketamina ( $8 \mathrm{mg} / \mathrm{kg}$ de peso vivo) (Gozalo, 1986; Creighton et al., 1987; Verlangieri et al., 1985). Los animales, luego de anestesiados, fueron pesados y se les colectó $2 \mathrm{ml}$ de sangre de la vena femoral.

Las muestras de sangre fueron llevadas al laboratorio del IVITA-Iquitos, para la obtención del suero por centrifugación a 3,000 rpm. Los sueros fueron congelados a $-20^{\circ} \mathrm{C}$ hasta su análisis en el Laboratorio de Patología Clínica de la Facultad de Medicina Veterinaria de la Universidad Nacional Mayor de San Marcos, Lima. Se determinaron los niveles séricos de bilirrubina, alanino amino transferasa (ALT), aspartato amino transferasa (AST), gamma glutamil transferasa (GGT), proteína total y albúmina, utilizando kit comerciales (Wiener Lab).

En el Cuadro 1 se muestra los resultados (promedios y rangos observados) de la bioquímica sanguínea de los monos Aotus.

Los valores de bilimubina total obtenidos en Aotus nancymae subadultos (0.76 \pm $0.05 \mathrm{mg} / \mathrm{dl}$ ) fueron similares a los valores obtenidos en diferentes cariotipos de esta especie y de Aotus vociferans (Baer et al., 1994), y los del mono aullador $(0.75 \mathrm{mg} / \mathrm{dl}$; Kaneko y Cornelius, 1971); aunque menores a los del mandril (0.16), chimpancé $(0.11)$, gorila $(0.14)$ y mono ardilla $(0.5 \mathrm{mg} / \mathrm{dl}$; Benjamín, 1991). Posiblemente, la diferencia que existe con los otros primates pueda deberse al ambiente donde se han desarrollado las especies (primates del viejo mundo), el tamaño, los hábitos alimenticios y el manejo en cautiverio. La mayor cantidad de bilirrubina no conjugada o libre encontrada en la sangre de los animales del presente experimento $(0.52$ 
Cuadro 1. Niveles séricos de bilirrubina, alamino amino transferasa, aspartato amino transferasa, gamma glutamil transferasa, proteína y albúmina en 30 monos Aotus nancymae criados en cautiverio. Iquitos

\begin{tabular}{lccc}
\hline & Unidad & Promedio & Rango \\
\hline Bilirrubina total & $\mathrm{mg} / \mathrm{dl}$ & $0.76 \pm 0.06$ & $0.51-1.36$ \\
Bilirrubina directa & $\mathrm{mg} / \mathrm{dl}$ & $0.25 \pm 0.03$ & $0.1-0.59$ \\
Bilirrubina indirecta & $\mathrm{mg} / \mathrm{dl}$ & $0.56 \pm 0.06$ & $0.1-1.23$ \\
Alamino amino transferasa & $\mathrm{UI} / \mathrm{L}$ & $30.65 \pm 5.50$ & $5-69$ \\
Aspartato amino transferasa & $\mathrm{UI} / \mathrm{L}$ & $36.90 \pm 5.69$ & $15-93$ \\
Gamma glutamil transferasa & $\mathrm{UI} / \mathrm{L}$ & $23.73 \pm 2.56$ & $11-33$ \\
Proteína total & $\mathrm{g} / \mathrm{dl}$ & $7.53 \pm 0.12$ & $6.9-8.1$ \\
Albúmina & $\mathrm{g} / \mathrm{dl}$ & $3.83 \pm 0.12$ & $3.2-4.3$ \\
\hline
\end{tabular}

$\pm 0.06 \mathrm{mg} / \mathrm{dl}$ ) con respecto a otros primates y mamíferos, podría deberse a factores tales como una mayor producción del pigmento que no necesariamente cursa con una enfermedad, o de una disminución en el aclaramiento hepático. En este último grupo hay enfermedades hereditarias que se caracterizan por la reducción de la actividad de la enzima glucoronil transferasa sin que haya ictericia clínica (García y Castejón, 1995; Benjamín, 1991).

Los valores de ALT encontrados en la literatura para monos del nuevo y viejo mundo son muy variables y con rangos grandes (Baer et al., 1994; Kaneko, 1980). En humanos el rango mayor aceptable es de $50 \mathrm{UI} / \mathrm{L}$ (Guyton, 1989).

Según Creigthon et al. (1987), la ALT es la enzima mejor indicada para detectar hepatitis aguda debido a HAV (virus de hepatitis A), donde los valores comienzan a elevarse a partir del cuarto día postinoculación hasta niveles de 259 y 613 UI/L entre los 11 y 74 días.
Los valores obtenidos de AST (36.9 $\pm 5,68$ UI/L) están dentro del rango conocido para chimpancés, pero son inferiores a valores reportados para el mono ardilla y el mono aullador (Kaneko y Cornelius, 1971). Los valores altos de AST están relacionados con necrosis de tejidos, tanto muscular como hepático.

Los valores obtenidos de ALT y AST en Aotus se asemejan a los de chimpancés juveniles (31.6 y $31.4 \mathrm{UI} / \mathrm{L}$, respectivamente; Baer et al., 1994). Esto es interesante e importante, porque después del chimpancé el Aotus resulta uno de los mejores modelos de experimentación que se asemeja al ser humano, y con la ventaja del mayor número poblacional y de su menor tamaño.

La GGT se emplea como un indicador de colestasis hepática. Los valores de GGT encontrados en este trabajo $(23.73 \pm 2.5 \mathrm{UI} / \mathrm{L})$ fueron similares a los valores obtenidos en monos Aotus en otros trabajos (Baer et al., 1994) aunque mayores a los reportados para Aotus trivirgatus (Creighton et al., 1987). 
Los valores obtenidos para proteína total $(7.53 \pm 0.12 \mathrm{~g} / \mathrm{dl})$ y albúmina $(3.83+0.12$ $\mathrm{g} / \mathrm{d} 1)$ estuvieron dentro de los rangos reportados para diversos cariotipos de Aotus (Baer et al., 1994).

Según Verlangieri et al. (1985), se observaron grandes variaciones en los parámetros sanguíneos de animales que han sido capturados en estado salvaje debido a lesiones subclínicas (parasitismo intestinal, microfilarias, malaria, etc.), infecciones previas y heridas mal tratadas. Además, se debe tener en consideración que las formas larvarias de los parásitos producen reacciones inflamatorias durante su migración por tejidos como el hígado, pulmón, cerebro y riñones, alterando los valores normales en sangre. En el presente trabajo, se debe considerar que la toma de muestras fue realizada en horas de la mañana, a pesar que estos animales son de hábitos nocturnos, y que debido a su temperamento nervioso se tuvo que anestesiarlos para poder tomar la muestra. Es así que el hecho de capturarlos, aplicar el anestésico y hacerlo en horas diurnas constituyen factores de estrés que pudieron haber alterado los resultados.

Se concluye que los valores obtenidos de bilirrubina, ALT, AST, GGT, proteína total y albúmina en primates Aotus nancymae, subadultos, criados en cautiverio y en condiciones climáticas de la selva peruana se encuentran dentro de los valores encontrados para estas especies por otros autores.

\section{Literatura Citada}

1. Aquino, R.; F. Encarnación. 1986. Estructura de la población de Aotus nancymae en tierras bajas de la Amazonía Peruana. Am. J. Primatology 11: 1-7.

2. Baer, J.F.; R. Weller; I. Kakoma. 1994. Owl monkey in oncogenic virus research. The Owl Monkey. p 145, 154, 255-259. Academic Press, USA.
3. Benjamín, M.M. 1991. Manual de patología clínica en veterinaria. $3^{\mathrm{a}}$ ed. $\mathbf{p}$ 275-300. Ed. Limusa. México.

4. Creighton, J.T.; J.W. Le Duc; E.C. Staley; L.N. Binn; R.H. Marchwicki; S.M. Lemon; C.M. Keenan; W.H. Bancroft. 1987. Induced oral infection of the owl monkey (Aotus trivirgatus) with hepatitis A virus. Lab. Anim. Sci. 37: 45-49.

5. Galvez-Durand, B.J. 2000. Medidas biométricas de Aotus nancymae nacidos en cautiverio. Tesis Bachiller. Fac. Med. Vet., Univ. Nac. Mayor de San Marcos. Lima, Perú. 33 p.

6. García, S.A.; F. Castejón. 1995. Fisiología veterinaria. p 588-598. Ed. McGraw Hill-Interamericana. Madrid, España.

7. Gozalo, A. 1986. Aspectos clínicos de la asociación de ketamina y xilacina en Aotus sp. La Primatología en el Perú. Investigaciones Primatológicas (19731985). Proyecto Peruano de Primatología "Manuel Moro Sommo", DGCF-IVITAOPS-OMS. Imp. Propaceb. Lima, Perú. $579 \mathrm{p}$.

8. Guyton, A.C. 1989. Fisiología y fisiopatología básicos. $9^{a}$ ed. p 961-966. Ed. McGraw Hill. USA.

9. Kaneko, J.; C.E. Cornelius. 1971. Clinical biochemistry of domestic animals. p 162, 164-206, 214-215. Academic Press. New York, USA.

10. Kaneko, J. 1980. Clinical biochemistry of domestic animals $3^{\text {rd }}$ ed. p 201-245, 792-794. Academic Press. New York, USA.

11. Organización Panamericana de la Salud (OPS) 1985. Conservación y reproducción de primates no humanos. Boletín OPS. 99. 423-428.

12. Soini, P. 1975. Resultados de una investigación preliminar de la fauna de la isla de Iquitos e islas adyacentes. La Primatología en el Perú, Investigaciones Primatológicas (1973-1985). Proyecto Peruano de Primatología "Manuel Moro 
Sommo", DGCF IVITA-OPS-OMS. Imp Propaceb. Lima, Perú.

13. Verlangieri, A.J.; J.C. DePriest; J.C. Kapeghian. 1985. Normal serum biochemical, hematological, and EKG parameters in anesthetized adult male Macaca fascicularis and Macaca arctoides. Lab. Anim. Sci. 35: 63-66.

14. Whitney, R.A. Jr. 1990. Conservación de primates no humanos y su importancia para la salud pública. Primates de las Américas. p 205-211. Ed. Battelle Press. Battelle Seattle Conference Center, Octubre $29-31$. OPS-OMS. Seattle Washington, USA.

15. Zamecnick, P.C. 1975. Primera conferencia interamericana sobre la conservación y utilización de primates no humanos en las investigaciones biomédicas. OPS-OMS Publ. Cient. 317. Lima, Perú. 